\title{
Resveratrol And Its Derivative Improves Oxidative Stress and Protects Against Alloxan- Induced Diabetics
}

\author{
Montaha A. Al-Safar \\ Medical Technical Institute/ Baghdad, Iraq.
}

\begin{abstract}
Resveratrol is a non flavonoid polyphenol and it has three phenolic hydroxyl groups and shown to have its biological effects. Reactive oxygen species play a crucial role in the pathogens of diabetes and its complication, this study aims to examine the effects of resveratrol and its derivative on alloxan induced diabetics. Statistical analysis showed a significant decrease in SOD, GSH, Gpx, Zn and Cu concentration and significant increase in MDA level on diabetic rabbits $p<0.05$, however diet supplemented with resveratrol derivative induced a significant increase of copper and zinc $1.43 \pm 0.01 \mathrm{ppm}, 0.79 \pm 0.02 \mathrm{ppm}$ respectively after sixth weeks of treatment as compared with control $1.13 \pm 0.03 \mathrm{ppm}, 0.66 \pm 0.01 \mathrm{ppm}$ respectively. . The administration of resveratrol derivative to rabbits resulted in the significant decrease of MDA levels after three weeks to $2.42 \pm 0.08$ nanomole $/ \mathrm{ml}$ and $1.56 \pm 0.02$ nanomole $/ \mathrm{ml}$ after sixth weeks as compared with control group $2.43 \pm 0.2778$ nanomole $/ \mathrm{ml}$. The diabetic rabbits presented a significant increase in the SOD activity after treatment by resveratrol derivative after sixth weeks $4.24 \pm 0.02 \mathrm{U} / \mathrm{ml}$ as compared with control during the experimental period, glbcimide treated group show a significant decrease in SOD activity after sixth weeks. In addition, there was a significant increase in Gpx activity119.77 \pm 0.01 U/L in resveratrol derivative treated group after sixth weeks. In infected animals was a decrease level of GSH when drug and purified resveratrol treated rabbits, while resveratrol derivative has normal value after three weeks of treatment $11.17 \pm 0.03 \mu \mathrm{mole} / \mathrm{L}$ and $19.82 \pm 0.01 \mu$ mole/L after sixth weeks. The results suggest thatresveratrol derivative may be helpful in preventing diabetic complications in rabbits.
\end{abstract}

Keywords: antioxidant enzymes, diabetic disease, oxidative stress, resveratrol.

\section{Introduction}

Resveratrol (RSV, 3,5, 4-trihydroxy stilbenes) is reported to be beneficial in diabetic Disease $[1,2]$. The beneficial effects are though to be due to its antioxidative properties because it is known as a robust scavenger of superoxide $\left(\mathrm{O}^{2-}\right)$, hydrogen radicals and peroxynitrite $[3,4]$. Oxidative stress, which is associated with the formation of lipid peroxides, is suggested to contribute to pathological processes in many diseases such as diabetes[5,6]. Diabetes is one of the pathological processes known to be related to an unbalanced production of ROS (Reactive Oxygen Species), such as hydroxyl radicals (HO), superoxide anions $\left(\mathrm{O}_{2}\right)$ and $\mathrm{H}_{2} \mathrm{O}_{2}$, therefore, cells must be protected from this oxidative injury by oxidative enzymes [7,8]. Antioxidant enzymes form the first line of defense against free radicals in organisms[9]. Erythrocytes contain a complex system of production against the action of ROS, its includes various enzymatic mechanisms, the most important anti oxidative enzymes of the Red blood cells are superoxide dismutase (Cu Zn -SOD ,EC 1-15-1-1), catalase (CAT ,EC 1-11-1-6) and glutathione peroxidase (GSH-P ${ }_{X}$ EC 1-11-1-9) [10]. Cu Zn- catalyzes the disruption of $\mathrm{O}_{2}$ - to hydrogen peroxid $\left(\mathrm{H}_{2} \mathrm{O}_{2}\right)$.GSH $-\mathrm{P}_{\mathrm{X}}$ can reduce lipid peroxides, under normal condition an equilibrium exists between the formation and removal ROS [11]. ROS are constantly formed in the human body and are removed by an antioxidant defense system, in healthy individuals the generation of ROS appears to be in approximate balance with antioxidant defense[12] . ROS are generally components, however at low concentration, ROS may function as physiological mediator of cellular response[13]. The aims of this study to examine the effects of resveratrol and its derivative on alloxan induced diabetics.

\section{MATERIALS AND METHODS}

Plant material : local black grapes were obtained from local market (Baghdad ) and classified as Vitis vinifera L belongs to the family Vitaceae by the herbarium of the Biology Department , College of Science ,Baghdad university, the method of Harborne [14] modified by[15], was used for the extraction of resveratrol. 
Preparation of resveratrol derivative : 5-(4-(4-(2-(benzo $\{d\}$ +hiozol-2-4L)hydra zinyl) butanoyloxy ) styryl ) -1,3-phenylene bis (4-(2-(benzo $\{\mathrm{d}\}$ thiozol -2-4L hydrazinyl ) butanoate. 1.6gm (0.003 mole ) of compound 2 * was dissolved in $50 \mathrm{ml}$ of absolute ethanol then added $1.58 \mathrm{~g}$ (0.0096 moles) of 2-mercaptombenzothazole and reflux for $8 \mathrm{hr}$. The solvent was removed and the precipitates was filtrated and dried [16].

Experimental desigein : Female rabbits (aged 10 week, weighing $1.80 \mathrm{Kg}$ ), they were maintained under standard aboratory condition ( $25^{\circ} \mathrm{C}, 12 \mathrm{hr}$. light / dark cycle ) with pellated food and tap water and libitum during 45 days of experimental period.

Induction of diabetes: fter 2 weeks of acclimatization ,diabetes was induced in female rabbits with a freshly prepared solution of alloxan monohydrate in normal saline at a dose $70 \mathrm{mg} \mathrm{kg}^{-1}$ body weight injected through the marginal vein of ear, because alloxan is capable of producing fatal hypoglycemia as a result of massive pancreatic insulin release, rabbits were orally treated with $20 \%$ glucose solution ( $5-10 \mathrm{ml}$ ) after $6 \mathrm{hr}$. , rabbits with moderate diabetes that exhibited glucosuria and hyperglycemia ( blood glucose con. 200-300 mg dl

- ) were taken for the experimental tests. After the successful induction of experimental diabetes the rabbits were divided into five groups comprising a minimum of six rabbits and treated as follow for six weeks:Animals in first group were received regular standard diet, tap water and severed as control (C). Rabbits in the $2^{\text {nd }}$ group were received alloxan, induced diabetic rabbits. A rabbit was considered to be diabetic ( D ).

Rabbits in the $3^{\text {rd }}$ group were received glbcimaid $(0.05 \mathrm{mg}$ ) orally, thus they formed the abbits of group 3 ( D G).Rabbits in the $4^{\text {th }}$ group were received resveratrol $1 \mathrm{mg} / \mathrm{ml}$ orally, thus they formed the rabbits of DR. While animals in the 5 group were received resveratrol derivatives $1 \mathrm{mg} / \mathrm{ml}$ orally, thus they formed the rabbits of DRD. The experimental protocol was approved by the institutional animal ethics committee of NRI Medical College and General Hospital in accordance with CPCSEA (Committee for the purpose and control and supervision on Experiments on Animals guidelines).

\section{Biochemical Assay:Estimation the concentration of copper and zinc in the serum}
The concentration
of copper
and zinc was
analyzed in Optical emission

spectrometry (ICP- OES)-a common used analyzing method for trace elements.

Measurement of Malonaldialdehyde( MDA) in plasma: Malonaldialdehyde levels were measured using the thioborbituric acid method[17], alculation were performed from the standard curve with 1,1,3,3tetramethoxypropene $(5-20 / \mathrm{L})$ for calibration.

\section{Antioxidant enzyme and glutathione assay in plasma}

SOD determination in serum. One unite of SOD was defined as the 50\% inhibition activity of SOD can be determined by calorimetric method, absorbance can be measured at 440nm.Calculation:

$\%$ inhibition $=\mathrm{A}$ control $-\mathrm{A}$ sample $/ \mathrm{A}$ control $\mathrm{x} 100$

\section{Estimation of glutathione peroxidase $\mathbf{G p}_{\mathbf{x}}$}

The $\mathrm{GP}_{\mathrm{X}}$ enzyme catalyzes the reduction of $\mathrm{H}_{2} \mathrm{O}_{2}$ to water and organic peroxides $(\mathrm{R}-\mathrm{O}-\mathrm{OH})$ to the corresponding stable alcohols using glutathione as a source of reducing equivalents. One unite will catalyze the oxidation by $\mathrm{H}_{2} \mathrm{O}_{2}$ of $1.0 \mathrm{Mole}$ of reduced glutathione to oxidized glutathione per minute at $\mathrm{pH} 7.0$ at $25^{\mathrm{O}} \mathrm{C}[18]$.

Estimation of Glutathione (GSH) in serum:GSH in serum was determined according to the modified by [19]. Which depends on using $\{5.5$ dithio bis (2-nitrobenzoic acid) $\}$ which reduced by sulfhydryl (SH group ) to yellow compound .The absorbance of the reduced chromogen was detected at $\square=412 \mathrm{~nm}$ and is directly proportional to the GSH concentration in serum .The concentration of GSH was then calculated by using :

GSH conc. $(\mu \mathrm{mol} / \mathrm{L})=\frac{\mathrm{AT}_{\mathrm{T}}=}{\square_{\mathrm{o}} \mathrm{XL}}$

Where: AT =test absorbance ; $\square_{\mathrm{O}}=$ extinction coefficient $=\left(13600 \mathrm{M}^{-1} . \mathrm{cm}^{-1}\right) \mathrm{L}=$ light path $=1 \mathrm{~cm}$ 


\section{Statistical analysis:}

Completely randomized design (CRC) program [20] was used to test the effect of the treatment on traits involved in this study. The least significant difference (LSD) test was also used to compare significance between the means [21].

\section{Results And Discussion}

Diabetes mellitus, the most common endocrine disease, is not a single disease but a group of disorders of varying etiology and pathogenesis current approaches of diabetes therapy involve mainly drugs enhancing insulin secretion while the role of antioxidants as the important agents restore the redox balance of the organism [22], while other studies have suggested that medical herbs may offer a similar degree of efficacy without so many troubles some side effects [23,24].Figure (1) there were significant decreased in zinc concentration in the drug treated group $(0.52 \pm 0.026 \mathrm{ppm})$ in comparison to the normoglycemic group $(0.66 \pm 0.02 \mathrm{ppm})$, the administration of resveratrol derivative to rabbits resulted in the significant increase of zinc $(0.79 \pm 0.02 \mathrm{ppm})$ after sixth weeks of treatment in comparison with control $(0.66 \pm 0.02 \mathrm{ppm})$. Other studies have suggested that the trace elements copper, zinc are linked together in cytosolic defense against reactive oxygen and nitrogen species, copper, zinc-superoxidedismutase catalyzes the dismutation of superoxide to oxygen and hydrogen peroxide $[25,26]$.

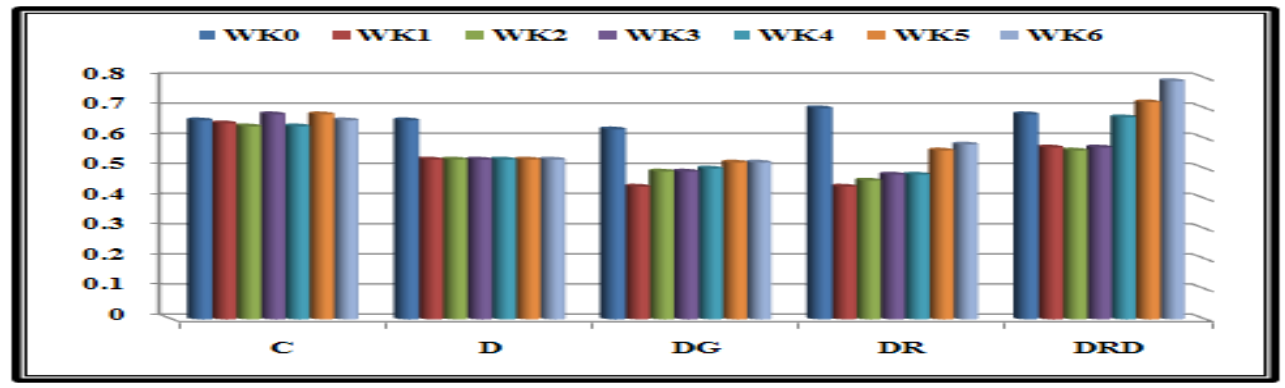

Figure (1): Bar chart of mean values of the Effect of Resveratrol derivative on serum Zinc Concentration (ppm) of treatment groups.

C=Control D=Diabetic DG=Diabetic after treated with glbcimide DR=Diabetic after treated with resveratrol $\mathrm{DRD}=$ Diabetic after treated with derivative .

\section{WK0=Pretreatment WK1=First week WK2=Second week WK3=Third week WK4=Fourth week WK5=Fifth week WK6=Sixth week.}

While copper concentration in the resveratrol derivative treate group significantly increased $1.31 \pm 0.03 \mathrm{ppm}$ after three weeks and $1.43 \pm 0.01 \mathrm{ppm}$ after sixth weeks in comparison to the control group $1.13 \pm 0.03 \mathrm{ppm}$ and the results was presented in figure (2). The role of copper ions are involved in both the generation of and the defense against reactive oxygen species (ROS) in cells [27] .

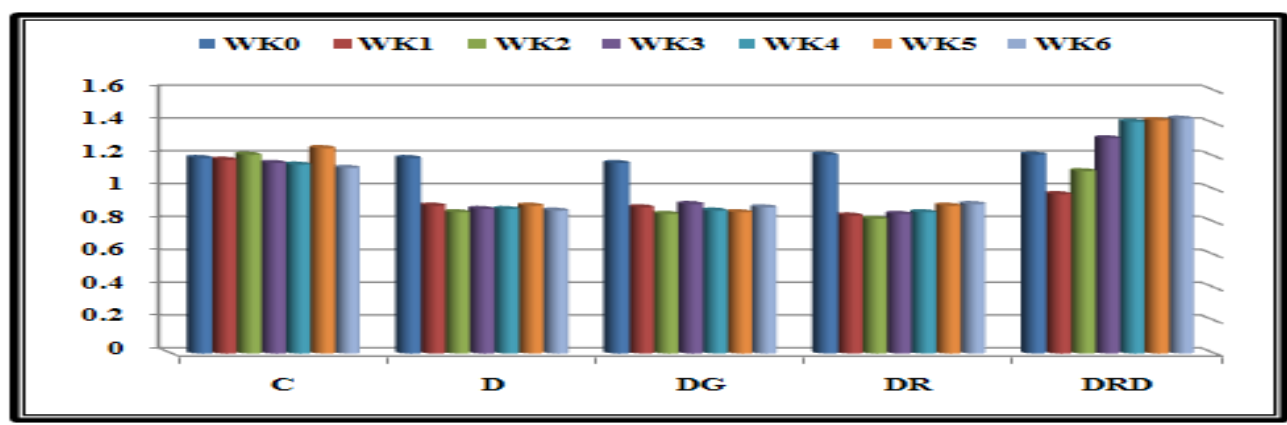

Figure (2): Bar chart of mean values of the Effect of Resveratrol derivative on Serum Copper Concentration (ppm) of treatment groups.

$C=$ Control $D=$ Diabetic $D G=$ Diabetic after treated with glbcimide $D R=D i a b e t i c$ after treated with resveratrol $\mathrm{DRD}=$ Diabetic after treated with derivative . 
In this study, there was significant increase in lipid peroxidation in diabetic group which was in agreement with others [22] and [28], resveratrol derivative shows significant value after three weeks of treatment $2.42 \pm 0.08$ nanomole $/ \mathrm{ml}$ in comparison with control $(2.43 \pm 0.2778$ nanomole $/ \mathrm{ml})$. the concentration of serum MDA in drug (glbcimide ) and purified resveratrol treated rabbits was clarified in Figure (3), the results showed decrease inthe MDA level in diabetic rabbits treated with glbcimide and purified resveratrol to $.44 \pm 0.1229$ nanomole/ml and 2.90 \pm 0.05 nanomole/ml respectively after sixth weeks.,.Moreover, following

intraperiteal injection of resveratrol, the concentration of MDA in acu-treated rabbits was significantly decreased both in purified resveratrol and resveratrol derivative, which medicates a powerful anti peroxidation effect of resveratrol[28,29]. The results indicate the increased lipid peroxidation under diabetic condition can be due to increased oxidative stress in the cell as a result of depletion of antioxidant protective systems[30,31]. The lipid peroxide mediated tissue damage has been observed in the development of all types of diabetes mellitus [27]

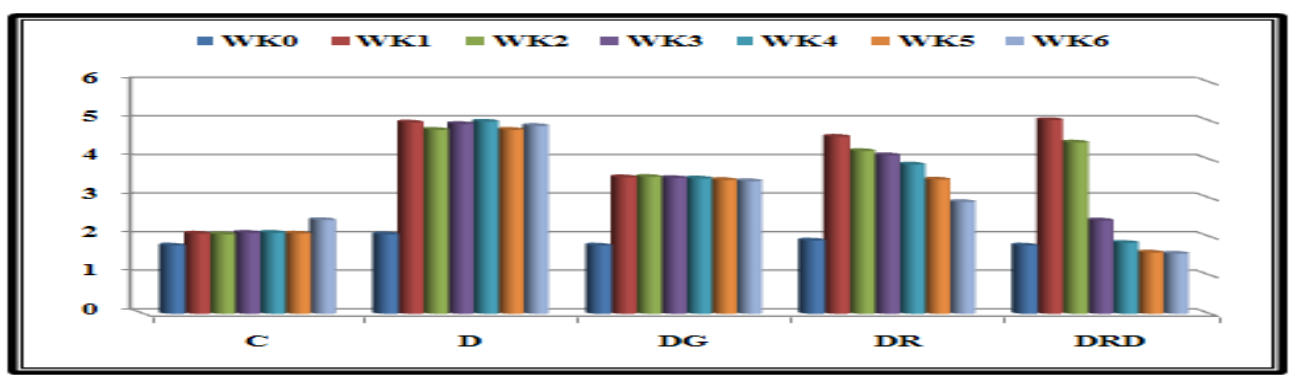

Figure (3): Bar chart of mean values of the Effect of Resveratrol derivative on Serum Malonyldialdehyde Concentration (nanomole/ml) of treatment groups. $\mathrm{C}=$ Control $\mathrm{D}=\mathrm{Diabetic}$ DG=Diabetic after treated with glbcimide $D R=$ Diabetic after treated with resveratrol $D R D=D i a b e t i c$ after treated with derivative .

In the present study there was a significant increase in SOD activity in resveratrol derivative treated group $(4.24 \pm 0.02) \mathrm{U} / \mathrm{ml}$ as compared with control during the experimental period, glbcimide treated group show a significant decrease in SOD activity $2.83 \pm 0.09 \mathrm{U} / \mathrm{ml}$ after sixth weeks of treatments as compared with the control $3.88 \pm 0.06 \mathrm{U} / \mathrm{ml}$, Figure(4), which shows that the derivative qualities have contributed to improving the effectiveness of the enzyme and that people with diabetes suffer from a high reduction in the level of antioxidant enzyme. From our results we concluded that resveratrol increases the activities of antioxidant enzyme in alloxan treated rabbits implying that resveratrol reactivates the antioxidant defense system, thereby increasing antidiabetic activity [27].

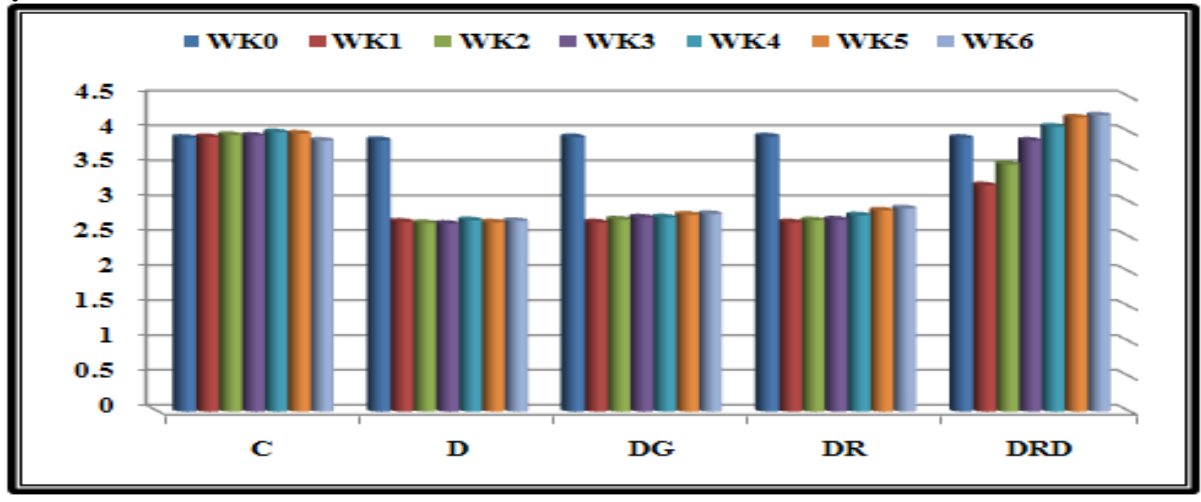

Figure (4): Bar chart of mean values of the Effect of Resveratrol derivative on Serum Superoxide dismutase activity (unit/ml) of treatment groups.

$C=$ Control $D=$ Diabetic $D G=$ Diabetic after treated with glbcimide $D R=$ Diabetic after treated with resveratrol $\mathrm{DRD}=$ Diabetic after treated with derivative .

Data on the effect of resveratrol derivative on $\mathrm{Gp}_{\mathrm{X}}$ activity are present in Figure(5).The increased activity of $\mathrm{Gp}_{\mathrm{X}}$ in resveratrol treated rabbits $93.96 \pm 0.07 \mathrm{U} / \mathrm{L}$ after three weeks as compared with control group $100.6 \pm 0.06 \mathrm{u} / \mathrm{ml}$ and 119.77 $\pm 0.01 \mathrm{U} / \mathrm{L}$ after sixth weeks, suggest that resveratrol has free radical scavenging activity, which may exert a beneficial effect against pathological alteration caused by reaction oxygen species .Ajith and Janaradhana 
(2001) mentioned in diabetes, non- enzymatic glycation due to persistent hyperglycemia may also inactivate the antioxidant enzyme, this results was in agreement with [32] . Regarding non - enzymic antioxidants, GSH is a critical determination to tissue susceptibility to oxidative damage and depletion of GSH has been shown to be associated with an enhanced toxicity to chemicals including diabetic status .

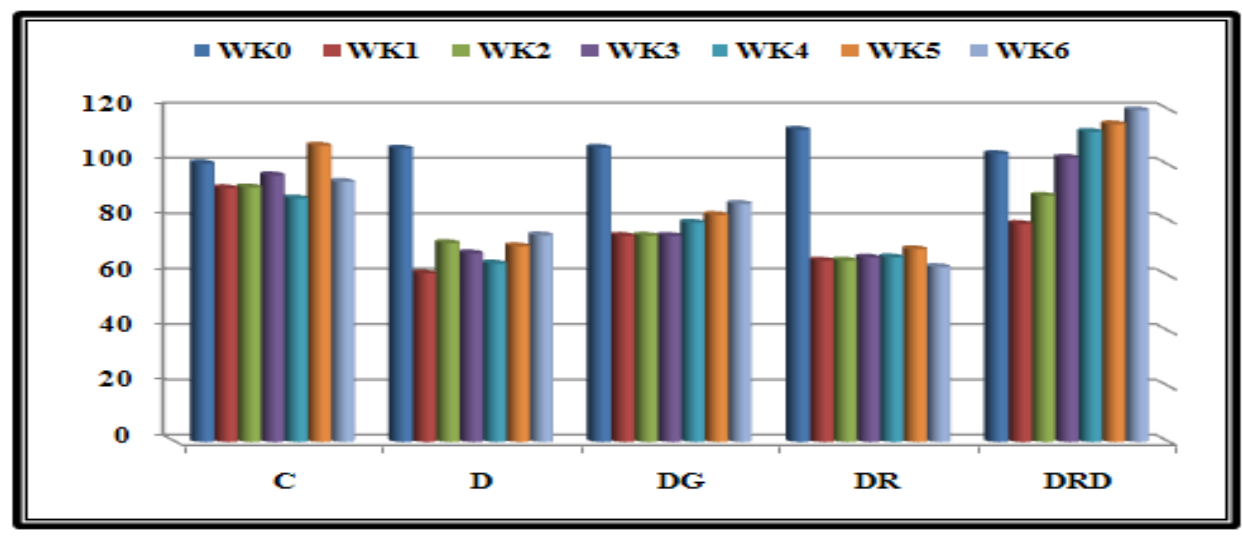

Figure (5): Bar chart of mean values of the Effect of Resveratrol derivative on Serum Glutathione Peroxidase activity (unit/L) of treatment groups.

\section{$C=$ Control $D=$ Diabetic $D G=$ Diabetic after treated with glbcimide $D R=$ Diabetic after treated with resveratrol $D R D=$ Diabetic after treated with derivative .}

Figure (6) it can be noticed that the infected animals was a decrease level of GSH when drug and purified treated rabbits $5.7467 \pm 0.02 \mu \mathrm{mole} / \mathrm{L}$ and $5.746 \pm 0.02 \mu$ mole/L respectively in comparison with control $10.66 \pm 0.05 \mu$ mole/L, while resveratrol derivative has normal value after three weeks of treatment $11.17 \pm 0.03 \mu$ mole/L and $19.82 \pm 0.01 \mu$ mole/L after sixth weeks, the increase in plasma GSH level in the DRD rabbits may be due to the novo GSH synthesis or GSH regeneration. The reducted glutathione, is required for activity of glutathione peroxidase and its quantity in case of oxidative stress is rather limited, that reduces the importance of this enzyme for the medical purposes [32]. The present finding strongly suggests that the use of resveratrol derivative helpful in preventing Diabetic complication in rabbits.These results are in accordance with other studies that the number of medical plant extracts possess as radical scavenging[33] .

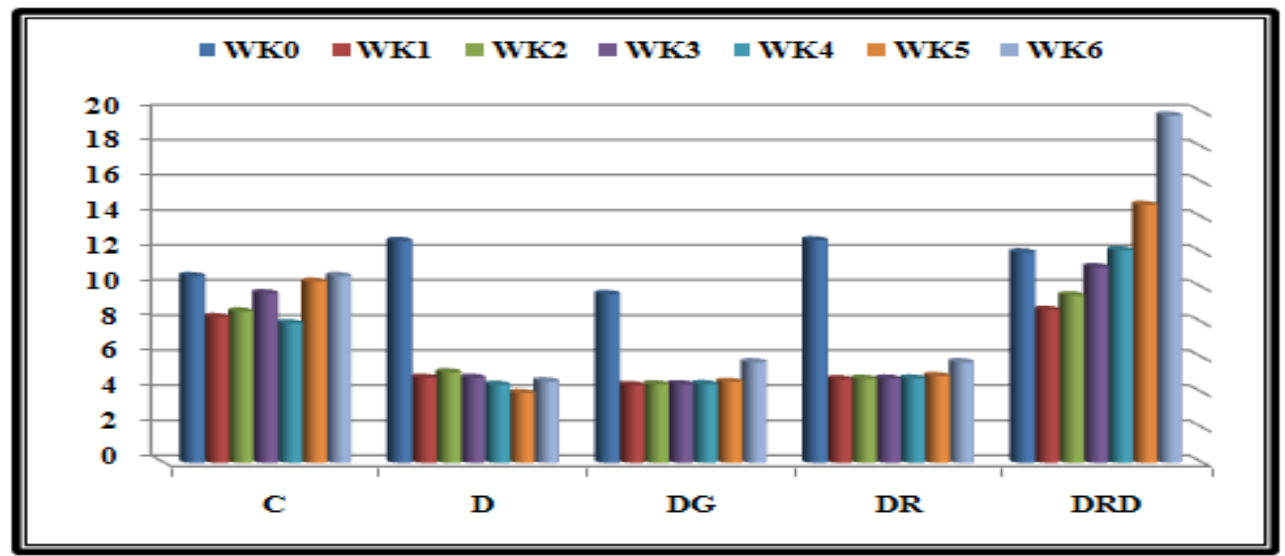

Figure (6): Bar chart of mean values of the Effect of Resveratrol and their derivatives on Serum Glutathione Concentration ( $\mu$ mole/L) of treatment groups.

$C=$ Control $D=$ Diabetic $D G=$ Diabetic after treated with glbcimide $D R=$ Diabetic after treated with resveratrol $\mathrm{DRD}=$ Diabetic after treated with derivative .

\section{Acknowledgment:}

The author thanks institute of genetic engineering and biotechnology for post graduated studies, to provide compound 2 used in the preparation of resveratrol derivative. 
List of abbreviation : $\mathrm{SOD}=$ Superoxide dismutase. $\mathrm{GSH}=$ Glutathion.GPx= Glutathion peroxidase. $\mathrm{Zn}=$ Zinc. $\mathrm{Cu}=$ Copper.ROS=Reactive oxygen species .CuZn-SOD= Copper , Zinc-Superoxide- dismutase.

\section{References}

[1]. Tomas-barberan, F.A. and Robins, R.J.(1997).Phytochemistry of fruit and vegetables.(Clarerdon press- Oxford. New York).

[2]. Ungvoeri Z, Orosz Z. and Rivera A (2007).Resveratrol increase vascular oxidative stress resistance.Am.Physiol.Heart Circ Physio. 292.

[3]. Mattivi F, Vrhovsek U, Malacarne G, Masuero D, Zulini L, Stefanini M, Moser C, Velsco R. and Guella G (2011). Profiling of resveratrol oligomers, important stress metabolites, accumulating in the leaves of hybrid Vitis vinifera (Merzling-Teroldego) genotypes infected with plasmopara viticola. Agric Chem 59, 5364-5375.

[4]. Rukmini M S, Benedicta D D. and Uivian D. (2004) .Superoxide dismutase and catalase activities and their correlation with malonaldehyde in schizophrenic patients. Ind Clin Biochem 19,114-118.

[5]. Ungvari Z and Csiszar A.(2011). Resveratrol confers endothelial prodection in insulin - dependent diabetes mellitus.Cardiovasc Drugs Ther 25, 111-113.

[6]. Sekeroglu M R, Sahin H, Dulger H. and Algun A. (2004) .The effect of dietary caloric restriction on antioxidant status and lipid peroxidation in mild and sever streptozotocin- induced diabetic rats.Clin Chem Acta 348, 121-129.

[7]. Silan C. (2008). The effect of chronic resveratrol treatment on vascular responsiveness streptozotocin - induced diabetic rats. Bio Pharm Bull 31, 897-902.

[8] Fendri C, Mechri A, Khiari G,Othman A, Kerkeni A. and Gaha L. (2006). Oxidative stress involvement in schizophrenia pathophysiology . Enephalo. 32, 244-252.

[9]. Mates J.M. and Sanchez -Jimenez F(1999).Antioxidant enzymes and their implications in path physiologic processes. Front Biosci .15, 339-345.

[10]. Mates JM, Perez-Gomez C. and Nanez de Castro I (1999).Antioxidant enzymes and human diseases. Clin. Biochem 32, 595-603.

[11] Louise AB, Cathrine JK, Paul W, Nicholas F, Jane M and Tony A. (2009).Oxidative stress regulates a dipocyte apolipoprotein E and suppresses its expression in obesity .J. Diabetes 57,2992-2998.

[12]. Keaney JFJr, Larson MG, Vasan RS and Wilson PWF (2003).Obesity and systemic oxidative stress :clinical correlates of oxidative stress in the Framingham study . Arterioscler. Thromb, Vasc.Biol.23, 434-439.

[13]. Shah PK and Patel J.A. (2010) Resveratrol and its biological actions .Review article .4(1):15-21.

[14] Harbone JB. (1984). Phytochemical methods, chapman and Hall London.

[15]. Al-Jumaily EF, Al-bayati RA and Shafiq ZA (2012). Antidiabetic and antihyperglycemia effects of Resvertrol and its Derivative on Alloxan diabetic rabbits. IOSR J of Pharmacy Vol.2, 50-58.

[16]. Stephen WW and Kelly, N. H.J. (2006) .Organic Chemistry . 71,1080.

[17]. Draper H H and Hodely M (1990).Malondialdehyde determination as index of lipid peroxidation . Methods in Enzymology 86, 421-443.

[18]. Wendel ,A. (1980 ). Enzymatic Basis of Detoxication, vol.1 :333. Academic Press, NY.

[19]. Jollow DJ, Mitchell JR, Zampaglione N and Gillete JR (1974). Bromobenzene induced liver necrosis:protective role of glutathione and evidence for 3,4 bromobenzeneoxide as the hepatotoxic intermediate . Pharmacology11, 151-168.

[20]. SAS, (2001). SAS/STAT User. Guide for personal computers. Release 6.12.SAS Institute Inc., Cary, Nc., USA. (SAS= Statistical analysis system).

[21] Steel RGD and Torrie JH (1980). Principle and procedures of statistics, Principle and Procedures of Statistics, McGraw-H.11Book Company Inc.

[22]. Sekeroglu MR, Sahin H and Dulger E (2000). .The effect of dietary treatment on erythrocyte lipid peroxidation , superoxide dismutase ,glutathione peroxidase and serum lipid peroxidation in patients with 2 diabetes mellitus. Clin. Bioche.33, 669674.

[23] Nihei T, Miura Y and Yagasaki, K(2001). Inhibitory effect of resveratrol on proteinuria, hypoalbuminemia and hyperlipidemia in nephritic rats. Life Sci.68, 2845-2852.

[24]. Willians LD, Burdock GA ,Edwards JA, Beck M and Bausch J (2009). Safety studies conducted on high -purity trans-resveratrol in experimental animals. Food Chem. Toxicol. 47, 2170-2182.

[25]. Makni M, Fetoui H, Gargouri NK, Garoui E. and Zeghal N. (2010). Antidiabetic effect of flax and pumpkin seed mixture powder: effect on hyperlipidemia and antioxidant status in alloxan diabetic rats. J. of diabetes and its complications. 25, 339-345.

[26]. Jin L, Xue HY, Jin LJ, Li SY, and Xu YP (2008) ). Antioxidant and pancreas-protective effect of aucubin on rats with Streptozotocin -induced diabetes .European J. of Pharmacology. 582, 162-167European J. of Pharmacology. 582, 162-167.

[27]. Ungvari Z , Labinskyy N, Mukhopadhyaye P, Pinto JT, Bagi Z, Ballabh P, ,Zhang C, Pacher P. and Csiszar A (2009) Am.J.Physiolo Heart Cur Physiol 279, 1876-81.

[28]. Akar F, Pektas MB, Tufan C, Soylemez S, Sepici A, Ulus AT, Gokalp B, Ozturk K,and Surucu HS (2010) ).Resveratrol shows vasoprotective effect reducing oxidative stress without affecting metabolic disturbances in insulin - dependent diabetes of rabbits. Cardiovasc.Drug Ther. 25 (2):119-131.

[29]. Jones SI and Janardhana KK (2000). Antioxidant and antitumor activity of G.lucidum (Curt:Fr)p. Karst -Reishi (Aphyllophoromycetideae) From south India. Int J Med Mushr 2, 195-200.

[30]. Ajith TA and Janaradhana KK (2001) Antioxidant and anti-nflammatory activities of methanolic extract of phoenix daetylifera .Indian J Exp Bio 39, 1166-1169.

[31]. Yun JM, Chien A, Jialal L and Devaraj S (2012) ). Resveratrol up_regulates SIRT1 and inhibits cellular oxidative stress in the diabetic milieu;mechanistic insights. The Journal of Nutritional Biochemistry 23, 699-705.

[32] Maksimenko AV, Vavaev AV and Tischenko EG (2010). Enzymatic antioxidants : Next phase of pharmacological effort of fight oxidative stress?.The Open Conference Proceeding Journal 1, 219-223.

[33]. Shehata A and Yousef O (2010) Physiological studies on the risk factor responsible for atherosclerosis in rats .Nature and Science $8,144-15$ 